\title{
Efectos de la llegada de flujos de inversión extranjera en el sector \\ hidroeléctrico colombiano
}

\section{Saúl Rick Fernández Hurtado, Karen Andrea Ochoa Ortiz, Luz Ángela Martínez Martínez}

\author{
Center for Global Studies \\ Shanghai University \\ Departamento de Economía, Contabilidad y Finanzas \\ Universidad Santiago de Cali \\ Departamento de Operaciones y Sistemas \\ Universidad Autónoma de Occidente, Cali
}

No es desconocido que el mundo actual se mueve en torno a la globalización de mercados; en este contexto, los flujos de inversión extranjera desempeñan un papel importante en el desarrollo económico de Latinoamérica, como es el caso de Colombia. En los últimos años, los flujos de inversión extranjera han generado un crecimiento no solo de carácter económico, sino en lo que respecta a las relaciones internacionales con el fortalecimiento de los tratados comerciales, y el intercambio de innovación en tecnología, procesos y conocimientos. De este modo, ha permitido que la economía tenga un desarrollo progresivo, lo que refleja que la inversión extranjera puede tener efectos positivos en el PIB del país.

La siguiente investigación está basada en una metodología descriptiva, a partir de la cual se evidencia el crecimiento de la inversión extranjera directa en el sector hidroeléctrico colombiano, lo que ha fomentado el fortalecimiento del sector desde el año 2012 hasta 2016. Para ello, se han desarrollado políticas de económicas y de protección sobre los recursos, que garanticen la prolongación de este sector. El resultado de la investigación refleja los efectos positivos de la inversión extranjera, que muestra un crecimiento del sector hidroeléctrico durante 2016, lo que está estrechamente relacionado con el PIB, al igual que el aumento de producción energética colombiana.

Palabras clave: inversión extranjera directa, economía colombiana, acuerdos comerciales, sector hidroeléctrico

\section{Effects of the influx of foreign investment flows in the Colombian hydroelectric sector}

It is known that the world today is moving around of the globalization of markets; it is there that foreign investment flows play an important role in the economic development of Latin America, as in the case of Colombia. In recent years, foreign investment flows have generated not only economic growth but also international relations with the strengthening of trade agreements, the exchange of innovation in technology, processes, and knowledge, allowing the economy to have a progressive development, reflecting that foreign investment can have positive effects on the country's GDP.

The research is based on a descriptive methodology, which shows the growth of foreign direct investment in the Colombian hydroelectric sector, encouraging the strengthening of the sector from 2012 to 2016, for which economic and resource protection policies have been developed to guarantee a continuation of this sector. The research results reflect the positive effects of foreign investment, showing a growth in the hydroelectric sector closely related to GDP in 2016, as well as the increase in Colombian energy production.

Keywords: Foreign direct investment, Colombian economy, trade agreements, hydroelectric sector 


\section{Efeitos da chegada de fluxos de investimento estrangeiro economia colombiana}

Não é desconhecido que o mundo hoje está se movendo em torno da globalização dos mercados; é onde os fluxos de investimentos estrangeiros desempenham um papel importante no desenvolvimento econômico da América Latina, como é o caso da Colômbia. Os fluxos de investimentos estrangeiros geraram no crescimento anos recentes, não apenas de natureza económica, mas nas relaçôes internacionais por meio do fortalecimento de acordos comerciais, intercâmbio de inovação em tecnologia, processos e conhecimento, permitindo a economia de ter um desenvolvimento progressivo, o que refletindo que o investimento estrangeiro pode ter efeitos positivos sobre o produto interno bruto (PIB) do país.

A pesquisa é baseada em uma metodologia descritiva, onde o crescimento do investimento estrangeiro direto no setor hidrelétrico da Colômbia é evidenciado através do incentivo ao fortalecimento do setor 2012-2016, este terá desenvolvido políticas e proteção econômica do recurso, para garantir a continuação deste sector, o resultado da pesquisa reflete os efeitos positivos do investimento estrangeiro crescimento exibição durante 2016 intimamente relacionados ao setor de energia hidrelétrica do PIB, como o aumento da produção de energia colombiana.

Palavras-chave: investimento estrangeiro direto, economia colombiana, acordos comerciais, setor hidrelétrico

\section{Introducción}

A través del tiempo, se ha generado la necesidad de identificar otras fuentes de ingresos en la economía colombiana y, en la actualidad, los flujos de inversión extranjera son bien vistos. Además de convertirse en una fuente de posibilidades mediante una buena gerencia administrativa, se puede generar mayor crecimiento económico y desarrollo en infraestructura, que, como consecuencia, puede fomentar el alza de empleos, así como una percepción de desarrollo y de competencia económica del país. Estos factores, a su vez, fomentarían más inversión de otras multinacionales, inversionistas independientes o entidades.

Este intercambio de flujo de inversión, generación de buenas relaciones entre países, tiene como consecuencia el permitir el intercambio de políticas económicas y monetarias, que buscan crear confianza en el mercado y un ambiente de estabilidad económica para el Colombia. Según Vanegas, Restrepo y Muneton (2012), con el tiempo, los efectos de los flujos de inversión van a "generar efectos positivos sobre la eficacia en la producción, la generación de empleo, la balanza de pagos y los ingresos tributarios». Frente a este contexto, es de gran importancia crear escenarios para que este tipo de inversión sea motivada a desarrollarse en el país, mediante acuerdos comerciales que generen beneficios a ambas partes; en este aspecto, es indispensable la estabilidad en las políticas comerciales y tributarias del gobierno de turno (Martínez-San Román, Bengoa y Sánchez-Robles, 2016).

Del mismo modo, se debe contar con los recursos necesarios - tanto de talento humano, como de producción y de políticas empresariales estructuradas- para poder ir acorde con la exigencia del capital invertido, puesto que, de una u otra manera, se está adquiriendo un compromiso de cumplimiento. A partir de este, se genera un acuerdo bilateral tanto del lado de la inversión extranjera como del lado de las empresas nacionales, ya sea por medio de una multinacional o una institución diferente, para invertir en una planta operativa y administrativa, o en organizaciones para el mejoramiento en la calidad de vida de sectores menos favorecidos (Rosas Chimal, Flores Ortega y Díaz-Bautista, 2015). Para ello, debe existir un control de los ingresos y la disposición de los mismos, puesto que algunas de las estrategias de inversión 
no son fructíferas, para lo cual se debe determinar un estudio que permita hacerlas medibles y crear un marco de los planes de inversión que tengan efectos positivos, así como de aquellos que tengan efectos negativos. Por medio de esta información, será posible identificar el desarrollo financiero y mejorar el acceso a estos (Desbordes y Wei, 2017).

A medida que se han realizado este tipo de negociaciones, tanto en Colombia como en otros países de Latinoamérica, se ha evidenciado el crecimiento y el desarrollo en la balanza comercial, y la potencialización de la economía de los países que reciben estos flujos de inversión extranjera; las nuevas investigaciones han mostrado que hay un amplio crecimiento macroeconómico de los regímenes cambiarios en pro de la balanza comercial que genera crecimiento de la economía (Abbott, Cushman y De Vita, 2012). Sin embargo, se hace necesario poder alinear las políticas de control sobre estos ingresos, debido a que, a pesar de los beneficios que puedan generar, no se pueden olvidar las repercusiones de volatilidad del cambio de la moneda, que tiene gran injerencia en la economía (esto se aplica para capitales golondrinos).

Debido a la crisis económica mundial vivida en los años 2008 y 2009, los países con capacidad de inversión empezaron a buscar mecanismos para diversificar sus capitales (Green y Livanos, 2015). De esta manera, nació la búsqueda de países emergentes que estuvieran experimentando un crecimiento en su entorno político y económico a través del tiempo, y que pudieran convertirse en una alternativa ideal de inversión (Tirado, 2015). No obstante, estos flujos de inversión extranjera tienen aspectos importantes a analizar, como el tipo de intereses que generan, su crecimiento y las posibilidades de recuperación de estas inversiones en el tiempo (Lim y Mohapatra, 2016), puntos que se desarrollarán más adelante.

\subsection{Problema de investigación}

En la actualidad, debido a que, producto de la globalización, los mercados están cada vez más correlacionados, se reduce el efecto de diversificación. A partir de ello, la globalización de los mercados y la búsqueda de escenarios productivos han llevado a que muchas empresas y entidades de origen extranjero tengan la necesidad de diversificar su portafolio de proyectos y obtener ganancias de los mismos. Una mirada a la economía colombiana da cuenta de una economía potencial y en desarrollo como un referente para inversión en empresas; carteras; o — simplemente- para cooperación con asuntos relacionados con la salud, educación y apoyo a otras causas. Este tipo de ingresos en el país se conocen como flujos de inversión extranjera, inversión que bien puede ser directa como indirecta. En el presente estudio, nos enfocaremos en la primera.

Una de las formas en que ocurre esta inversión directa es mediante la realización, y la construcción de plantas y oficinas por parte de las empresas multinacionales extranjeras, a partir de lo cual se generan activos fijos en Colombia, y se crean fuentes de empleo informales que motivan la circulación de dinero, que, a su vez, pone en movimiento a la economía del país (Plaza Martínez, 2014). Otro modo en que se da esta inversión extranjera es a través de las carteras de inversión, que suponen la colocación de capitales en el mercado accionario, y la adquisición de bonos por parte de inversionistas individuales o particulares.

Este tipo de operaciones se ven reflejadas de una o de otra forma en la economía colombiana y, por ende, afectan la operación de la balanza comercial colombiana (Lagos Cortes y Vecino Arenas, 2014) en la economía interna. Incluso, pueden afectar la vida misma de las personas que están alrededor de estas operaciones. Este efecto será el principal objetivo de este 
estudio, que apuntará a analizar de qué forma el flujo de inversión directa puede impactar, ya sea de manera positiva o negativa, en la economía colombiana.

En una economía emergente como la colombiana, es de suma importancia servirse de convenios que promuevan crecimiento económico al país. Además del proceso de posconflicto y reconciliación que requerirá de un proceso de inclusión, es necesario generar fuentes de empleo para todo aquel que desee dejar las armas. Este panorama hace de Colombia un país más atractivo y seguro, expectante a las posibilidades de adquirir socios inversionistas (Fuentes Soriano, Ruiz-Giardín y Sanz, 2006). Lo anterior crea un fortalecimiento a la economía, debido a que el incremento de inversión extranjera directa se convertirá en un músculo económico de crecimiento para el país.

Los flujos de inversión extranjera directa son una excelente posibilidad de desarrollo para la economía colombiana. Sin embargo, se debe tener en cuenta cuáles son los sectores que más se pueden desarrollar (Garavito, Iregui y Ramírez, 2014), qué implicaciones o qué reestructuras deben aplicarse a las políticas comerciales y macroeconómicas del país para que estos flujos de inversión puedan ingresar sin problemas. Tener los profesionales aptos para que puedan estar frente al desarrollo de los proyectos de estas inversiones implica una modificación de la visualización de la economía en todos sus aspectos (Martínez-San Román et al., 2016).

\section{Marco teórico}

De acuerdo con el tema planteado, se requiere conocer qué son los flujos de inversión extranjera, cuáles son las modalidades de estos en Colombia, cuál ha sido el comportamiento de estos durante los últimos diez años y cuál es el panorama a futuro.

\subsection{Flujos de inversión extranjera directa}

Los flujos de inversión extranjeras (IED), según el Banco de la República (2017a y b), son una clase de inversión de carácter internacional, lo que supone que un extranjero inversionista adquiere rentabilidad sobre una empresa nacional. Dicha inversión cuenta con un amplio control, que se mide dependiendo de la participación activa o la inversión que adquiera de la empresa. En ese marco, se debe tener en cuenta el porcentaje de acciones adquiridas por el inversionista. Estas inversiones directas son transacciones generalmente a largo plazo, son altamente estables y tienen menor sujeción de factores coyunturales.

La IED es de vital importancia como fuente de financiación externa para la economía de un país, puesto que esta puede tener efectos positivos en el crecimiento económico y, por ende, en la balanza de pagos a largo plazo para el crecimiento de mercado nacional. Estas también pueden incrementar el desarrollo tecnológico y la competitividad, mejorar la calificación de la mano de obra y fomentar la formación de capital; como consecuencia de ello, es posible disminuir los costos operativos, características que hacen atractiva la inversión extranjera (Fernández, 2013; González Molina, 2015).

\subsection{Acuerdos comerciales y fortalecimiento del comercio exterior}

Para que la inversión extranjera sea posible en Colombia, se han implementado políticas de comercio exterior, además de acuerdos internacionales de inversión (también conocidos como AII) (WillsValderrama, 2011), que permiten que la inversión cuente con la derivada protección y promoción. También, se cuenta con los tratados de libre comercio que hasta la fecha se han firmado en lo que respecta 
a la inversión y la doble tributación para la protección de las economías de los países implicados en el mismo.

Este tipo de políticas de comercio exterior permiten el desarrollo de una integración económica, que se encuentran definidos en los últimos tres planes nacionales de desarrollo. Estos son los cambios que han sido necesarios realizar para hacer de la economía colombiana una economía más abierta a la globalización que exige el mercado mundial (Gutiérrez Haces y Quintero, 2016). La tabla 1 muestra los acuerdos vigentes en los que Colombia ha participado para la promoción y la protección recíproca de las inversiones, suscritos o en negociación (Gazol Sánchez, 2016).

Las IED pueden contribuir con el fortalecimiento del comercio internacional. Este fenómeno se produce a partir del intercambio entre las empresas receptoras de inversión por medio de las exportaciones, que se ven incrementadas en mayor medida a nivel internacional. Esto, también, impacta en las empresas nacionales, aunque también depende de los bienes a intercambiar,

Tabla 1. Acuerdos para la promoción y protección recíproca de las inversiones, suscritos o en negociación

\begin{tabular}{|c|c|c|c|}
\hline APRRI & Entrada en vigencia & Ley aprobatoria & Estado del tratado \\
\hline $\begin{array}{l}\text { Capítulo XVII del TLC G2 } \\
\text { (México y Colombia) }\end{array}$ & 1995 & Ley 172 de 1994 & $\begin{array}{l}\text { En vigor. Sentencia de Constitucionalidad } \\
\text { C-178 de } 1995\end{array}$ \\
\hline Capítulo IX del TLC Chile & 2009 & Ley 1189 de 2008 & $\begin{array}{l}\text { En vigor. Sentencia de Constitucionalidad } \\
\text { C- } 031 \text { de } 2009\end{array}$ \\
\hline $\begin{array}{l}\text { Capítulo XII del TLC } \\
\text { Triángulo Norte (Guatemala, } \\
\text { El Salvador y Honduras) }\end{array}$ & $\begin{array}{l}\text { Guatemala: } 2009 \\
\text { El Salvador: } 2010 \\
\text { Honduras: } 2010\end{array}$ & Ley 1241 de 2008 & $\begin{array}{l}\text { En vigor. Sentencia de Constitucionalidad } \\
\text { C-446 de } 2009\end{array}$ \\
\hline APPRI España & 2007 & Ley 1069 de 2006 & $\begin{array}{l}\text { En vigor. Sentencia de Constitucionalidad } \\
\text { C-309 de } 2007\end{array}$ \\
\hline APPRI Suiza & 2009 & Ley 1198 de 2008 & $\begin{array}{l}\text { En vigor. Sentencia de Constitucionalidad } \\
\text { C-150 de } 2009\end{array}$ \\
\hline $\begin{array}{l}\text { Capítulo X del TLC Estados } \\
\text { Unidos }\end{array}$ & 2012 & $\begin{array}{l}\text { Ley } 1143 \text { de } 2007 \text { (Protocolo } \\
\text { Modificatorio Ley } 1166 \text { de 2007) }\end{array}$ & $\begin{array}{l}\text { En vigor. Sentencia de Constitucionalidad } \\
\text { C-751 de } 2008\end{array}$ \\
\hline Capítulo V del TLC EFTA & 2010 & Ley 1372 de 2010 & $\begin{array}{l}\text { En vigor solamente para Liechtenstein y } \\
\text { Suiza. Sentencia de Constitucionalidad } \\
\text { C-941 de } 2010\end{array}$ \\
\hline Capítulo VIII del TLC Canadá & 2011 & Ley 1363 de 2009 & $\begin{array}{l}\text { En vigor. Sentencia de Constitucionalidad } \\
\text { C- } 608 \text { de } 2010\end{array}$ \\
\hline APPRI Perú Profundizado & 2010 & Ley 1342 de 2009 & $\begin{array}{l}\text { En vigor. Sentencia de Constitucionalidad } \\
\text { C-377 de } 2010\end{array}$ \\
\hline APPRI China & 2012 & Ley 1462 de 2011 & $\begin{array}{l}\text { En vigor. Sentencia de Constitucionalidad } \\
\text { C-199 de } 2012\end{array}$ \\
\hline APPRI India & 2012 & Ley 1449 de 2011 & $\begin{array}{l}\text { En vigor. Sentencia de Constitucionalidad } \\
\text { C-123 de } 2012\end{array}$ \\
\hline APPRI Reino Unido & Pendiente & Ley 1464 de 2011 & $\begin{array}{l}\text { Sentencia de Constitucionalidad C- } 169 \text { de } \\
\text { 2012. Pendiente proceso de aprobación en } \\
\text { el Reino Unido }\end{array}$ \\
\hline
\end{tabular}

Fuente: Procolombia (2017a). Elaboración propia. 
que pueden ser materias primas o bienes realizados con piezas importadas, o -inclusive- servicios. Estas operaciones llegan a tener gran relevancia en el resultado de la balanza comercial de Colombia y en su PIB per cápita (Díaz Castro, 2013).

En general, se puede afirmar que tanto el gobierno - con la implementación de políticas de comercio exterior - como los empresarios han realizado los esfuerzos necesarios para estar en las condiciones necesarias que permitan aprovechar toda oportunidad de obtener inversión extranjera.

En Colombia, la Dirección de Desarrollo Empresarial (DDE), entidad gubernamental, se encarga de todos los temas vinculados con el comercio exterior e inversión extranjera en Colombia. Esta entidad busca mecanismos para desarrollar la integración económica en el país, no solo con multinacionales, sino que busca diversificar el mercado de las pequeñas y medianas empresas en cuanto a bienes y servicios (Corbella y Sarmento G. de Souza, 2017), mediante la creación de políticas de comercio exterior que hagan asequible el comercio internacional.

La meta de este tipo de entidades es la construcción de una visión a futuro de los sectores productivos de las empresas colombianas, a partir de un plan de trabajo que incluye orientación, implementación, seguimiento y evaluación de los planes planteados. De este modo, se diseñan espacios de capacitación para los empresarios, que son de vital importancia para la proyección de las empresas que trabajan para participar en el comercio exterior a través de la inversión extranjera (Yepes, 2014).

Estos acuerdos se han logrado mediante los esfuerzos del equipo negociador del Ministerio de Comercio Exterior, que realiza una investigación para saber qué tan beneficiosos pueden ser estos tratados para la eco- nomía de nuestro país. Después de ser discutidos, aprobados y ratificados, serán regulados por la Constitución Política de nuestro país, y del país o países con quienes se firme el acuerdo. La negociación es un proceso en que no solo interviene el gobierno; también, entran otros actores, como los empresarios, los gremios de producción, las organizaciones sociales, las universidades y el mismo Congreso de la República. Entre estas entidades, se lleva a cabo un proceso de investigación y de intercambio que toman en cuenta el presidente y sus ministros a la hora de firmar un tratado (Álvarez, 2016).

\subsection{Innovación y desarrollo tecnológico}

La innovación y la tecnología son un medidor del desarrollo de un país, que reflejan inversión y crecimiento. Aunque Colombia trabaja en el mejoramiento de ambas, se hace absolutamente necesaria la inversión de capital para poder promover el crecimiento productivo (Levy Orlik, 2016).

Las empresas extranjeras pueden ofrecer al mercado colombiano el desarrollo de procesos de producción más modernos y tecnificados, y la implementación de técnicas de gestión. Del mismo modo, pueden promover la capacitación de empleados, ya sea dentro o fuera del país, que derive en mano de obra mejor calificada a nivel nacional e internacional para competir en el mercado. Esto se puede traducir en una mayor posibilidad de destacar o estar al nivel de las mejores empresas en un mercado globalizado, que, día tras día, se desarrolla a pasos agigantados (Blanco Rangel, 2013).

Estudios del Banco Mundial (Chonchol, 1998) señalan que, en los sectores en los cuales tienen mayor participación las empresas multinacionales, se perciben las mejoras en cuanto a productividad y tecnología. De este modo, dichos sectores se posicionan en el mercado nacional a través de la dinámica 
inversionista. Ello permite el desarrollo industrial y tecnológico de los países que están dispuestos a ir acorde con las exigencias mundiales.

La inversión extranjera directa es uno de los recursos que pueden aprovechar los países y las empresas para poder realizar un intercambio tecnológico entre ellos (Becerra Rodríguez, Serna Gómez y Naranjo Valencia 2013; Fernández 2014). Cabe anotar que las empresas transnacionales siempre están buscando el mejoramiento de sus procesos y la reducción de costos. Esto se logra en muchas ocasiones mediante la apertura de una nueva filial en otro país que ofrezca incentivos para la creación de empresa. Como afirma Serrano (2012), «La deslocalización industrial, entró a jugar un papel sustancial en los cambios globales de producción, sectores industriales de gran importancia en los países desarrollados ya se habían deslocalizado desde antes de la liberalización económica».

El desarrollo y la innovación tecnológica no tendrían ninguna influencia en la economía de un país si esta no generara ningún beneficio a la humanidad. La generación de tecnología es el mayor mecanismo dentro del proceso de innovación. Las economías más desarrolladas en el mundo, generalmente, están sustentadas en el desarrollo tecnológico y en la innovación. Igualmente, las multinacionales siempre buscan la expansión de sus filiales a otros países para permitir que el desarrollo tecnológico beneficie a países en crecimiento económico, como es el caso de Colombia. Es un proceso que requiere de la transmisión de conocimientos y en el que, en muchas ocasiones, se da la movilidad de capital humano para difundir información de innovación (García-Pérez de Lema, Gálvez-Albarracín y Maldonado-Guzmán, 2016).

Las bases políticas para la implementación de la innovación y el desarrollo tecnológico están dadas

mediante la construcción de un plan estratégico de desarrollo tecnológico industrial y de calidad, que ayuda a determinar los lineamientos que permiten que este crecimiento tecnológico tenga una evolución positiva para el país, no solo en el sentido del desarrollo como las prácticas de las tendencias tecnológicas internacionales, sino también en términos de la sostenibilidad ambiental (Gálvez Albarracín y García Pérez de Lema 2012), que fomenta el buen crecimiento de las mismas. Esto, además, redirecciona las actividades industriales y tecnológicas en el país, a partir de lo cual las hace más competitivas.

\subsection{Desarrollo progresivo del mercado nacional y el PIB per cápita}

Para Stumpo (1999), el desarrollo económico que puede generar el flujo de inversión extranjera, se ve afectado por las restricciones del país, lo cual produce un desacuerdo inicial entre el mercado doméstico y la estructura de un nuevo mercado. Sin embargo, con el desarrollo de estrategias de mercado y del comercio internacional, es posible que un nuevo producto o servicio se adapte al mercado nacional. Además de ello, se puede alcanzar a estructurar una reducción de costos (aunque, también, el efecto podría ser contrario: mayor productividad de la IED genera un incremento en el costo de los factores de producción, lo cual afecta negativamente a los sectores de baja productividad). Ello genera una producción más atractiva, que lleva a que el mercado doméstico replantee estrategias para estar acorde con la competencia del mercado global (Contreras-Pacheco, Pedraza Avella y Martínez Pérez, 2017).

Esto no implica que, en todos los casos, el nivel de eficacia de las multinacionales se vea reflejado en una reducción de costos, o que su producto o servicio sea el que muestre el mejor desempeño en el mercado. 
En muchas ocasiones, la fuerza del producto se puede observar en algún otro tipo de ventaja, ya sea por medio de una patente o de una tecnología exclusiva de la empresa, que satisfaga la necesidad de un nicho de mercado en especial, que no tendrá ningún tipo de afectación sobre el sector del mercado nacional (Cordera Campos, 2014).

De acuerdo con lo anteriormente expuesto, los flujos de inversión extranjera directa pueden producir diferentes efectos sobre la economía de Colombia, a partir de lo cual podemos distinguirlos entre efectos directos y efectos indirectos. A partir de los efectos directos, se puede observar cómo esta economía puede incrementar los niveles de empleo (siempre y cuando no afecten a los sectores de baja productividad) y de productividad al país, lo que crea una señal del crecimiento positivo sobre el PIB (Torres, 2013). De este modo, a través de la circulación de dinero, se amplía el mercado local. De forma similar pero indirecta, este tendrá un impacto en la producción, puesto que se implementarán nuevas estrategias que pueden ser económicas o tecnológicas. Ello, básicamente, depende del interés de la empresa inversionista en el crecimiento y la proyección en tiempo que considere que su empresa pueda necesitar en el país (Gómez Toro, 2014).

La economía de Colombia cuenta actualmente con una serie de condiciones que hace que los inversionistas extranjeros la vean más atractiva. Entre los aspectos atractivos, se encuentran los aranceles que están negociados en los tratados, además de los regímenes arancelarios especiales y la posibilidad de ampliar el mercado en Latinoamérica, debido a que Colombia se encuentra en una excelente ubicación geográfica que permite considerar varias posibilidades de despacho para las exportaciones - gracias a que cuenta con puertos en el Pacífico y en el Atlántico- (Escandón Barbosa y Hurtado Ayala, 2014).

\section{Determinar cómo se dan los flujos de inversión extranjera directa en Colombia}

\subsection{Flujos de inversión extranjera directa en Colombia}

Desde 1970, se ha discutido acerca de los flujos de inversión directa en Colombia. En esa época, la inversión en su mayoría fue dirigida hacia la industria petrolera y sus derivados. A partir de 1991, y con toda apertura que ese año trajo consigo, tanto en el comercio exterior como en las nuevas leyes implementadas para ser asequibles a este comercio globalizado, la inversión extranjera directa se pudo diversificar, y adquirió mayor relevancia para la economía del país y para los diferentes sectores económicos de este. Sobre esta base, comenzamos a analizar cómo la inversión extranjera ha impactado en la macroeconomía del país, que se ha constituido actualmente en un portafolio de productos y servicios que se pueden generar en Colombia para suplir las necesidades de otros mercados.

Con la apertura al comercio internacional, que comenzó con la creación del Ministerio de Comercio Exterior en 1991, se crearon las condiciones para generar disposiciones legales que permitieran ampliar la inversión extranjera en Colombia; ejemplo de ello es la Ley 9 de 1991. Mediante estas disposiciones, se fomentó de manera inmediata un incremento de los flujos de inversión extranjera directa: el Banco de la República había estimado para ese año una inversión de US\$ 438 millones y, para 1996, esta ascendió a US\$2972. Este crecimiento tuvo un impacto positivo en el capital de formación del PIB, que ascendió de un 1,4\% en 1990 hasta alcanzar el 3,5\% en 1996, un cambio bastante considerable y positivo para el desarrollo de la economía colombiana.

En 2014, Colombia recibió aproximadamente el $8 \%$ de la inversión extranjera de Latinoamérica y, 
en año 2013, fue el cuarto destino de IED, después de Brasil, Chile y México, además de ser el país con más empresas trasnacionales pertenecientes a la misma región. Estos méritos se encuentran profundamente ligados con los cambios en las leyes de comercio exterior y a los tratados pactados.

Cabe considerar que la inversión extranjera directa en Colombia ha tenido una amplificación en los sectores con el paso de los años. En la década de 1980, la mayor parte de la inversión estaba dirigida a la industria petrolera y a los diferentes campos donde esta se concentraba, como en Cusiana y Cupiagua. En ese período, ingresaron empresas como Company Texas, que explotó este recurso natural y obtuvo el máximo provecho de ello. Sin embargo, en la actualidad, existen otros sectores que se han visto fuertemente influenciados por la inversión extranjera, como el sector financiero o el sector público, en el que destacan empresas como Isagen - que recibió una fuerte inversión de capital canadiense recientemente- (este tema se desarrollará más adelante). Esto trae como consecuencia otros procesos de modernización y restructuración de sus sedes en Colombia, pero la mayor concentración de inversión se encuentra en la diversificación del mercado financiero.

A pesar de la crisis económica internacional en los años 2008 y 2009, que generó una baja en la inversión en los períodos posteriores, Colombia y su economía jamás han desaprovechado la inversión extranjera en la economía de las organizaciones industriales. Se sabe cuán positivos son los efectos de estas inversiones y cómo estas pueden desempeñar un papel importante en la apertura al mercado global, tecnificando e innovando el sector, lo que supone ventajas para la competitividad, y repercute en los costos y los beneficios que además generará para el inversionista.
Existen varios ámbitos a mejorar para poder ampliar el portafolio de inversión extranjera. Para ello, es necesario una revisión y modificación de la legislación de comercio internacional (Álvarez, 2016). A su vez, se deben regular y crear políticas que incentiven la inversión extranjera, ya sea con beneficios tributarios o que incluyan concesiones que beneficien al inversionista, $o$ mediante la excepción de derechos de importación o exportación. También, se pueden promover subsidios al capital (reflejados en disminución de impuestos) y a los salarios. Este tipo de medidas no solo favorecerán al empresario que tenga al país como perspectiva, sino a la propia economía, puesto que de esta se deriva el incremento de empleos para personas que estén calificadas para desempeñar cargos que necesiten estas empresas. A partir de ello, es posible generar las condiciones favorables para incentivar este tipo de movimiento de dinero y de conocimientos. De este modo, se puede establecer una diferenciación en relación con los demás países de la región, lo que permite que esta economía sea más atractiva sin afectar los sectores internos de la economía.

El impacto macroeconómico que estas inversiones directas pueden fomentar se puede considerar de dos maneras, de acuerdo con Vanegas et al. (2012): como parte del resultado de una formación de capital adicional y mediante la financiación de la balanza de pagos. De esta manera, los autores indican que se pueden aplicar ambos tipos de inversión al mismo tiempo, generando beneficios al sector.

Igualmente, otro de los aspectos por los cuales Colombia tiene ventajas en cuanto a la inversión extranjera directa se relaciona con sus recursos naturales. Para muchos de los inversionistas, son muy atractivas las fuentes de recursos naturales con las que cuenta Colombia y han sabido explotarlas desde 1988. El principal recurso ha sido el petróleo y sus derivados, 
como el carbón, los metales preciosos, las piedras preciosas; incluso, las manufacturas han tomado fuerza por su calidad. En la actualidad, las fuentes hídricas han tomado mucha importancia, no solo por el agua como recurso natural, sino por la trasformación que esta puede llegar a tener con los equipos y la tecnología necesaria. Al ser en sí misma una fuente de energía, en la actualidad, muchos países la perciben como un bien preciado.

Tan pronto como se ponen a la venta empresas de este tipo de recursos, los países o inversionistas interesados plantean sus mejores propuestas para poder adquirirlas. Esto genera un incremento en los proyectos y promueve nuevos inversionistas para la economía colombiana. Por estos motivos, es necesario que Colombia siga desarrollando ventajas tanto competitivas como comparativas para poder tener los suficientes argumentos al momento de captar inversionistas extranjeros.

Según Procolombia (2013), entre enero y marzo de 2016, se recibieron inversiones extranjeras directas por valor de US\$ 4269 millones. De ellos, solo el $6,5 \%$ de la inversión pertenecía al petróleo, mientras que el restante $93,5 \%$ correspondía a otros sectores. El sector de mayor influencia fue electricidad, gas y agua, con un 53,3\%; seguido por transportes, alimentos y comunicación, con un 16,8\%; manufacturas, con un $9,1 \%$; petróleo y minas, con un $7,0 \%$; otros sectores, con $6,0 \%$; y, por último, sectores financieros, con un $4,7 \%$. De este modo, se observa que, en la actualidad, Colombia cuenta con un portafolio de productos y servicios para inversión extranjera directa bastante diverso. Esto se ha logrado mediante la creación de seguridad y de garantía en los inversionistas, gracias a los tratados bilaterales de protección a la inversión extranjera (ver tabla 1) que se han suscrito. Además, se ha afiliado a institutos, como la Agencia de
Garantías Multilaterales de Inversión (conocida como MIGA24) y también el Centro Internacional de Arreglo de Conflictos Relativos a la Inversión (conocido como Ciadi).

Sin embargo, no solo basta con estos esfuerzos por parte de las organizaciones gubernamentales, como la inversión para el desarrollo de la infraestructura necesaria - como puertos, carreteras y zonas francas-; además, se necesitan políticas macroeconómicas para poder recibir la inversión extranjera. Para que toda esta investigación no sea en vano, es necesario que contemos con el recurso humano o la mano de obra calificada que fomente innovación y desarrollo tecnológico, así como la maquinaria y la tecnología necesarias que permitan aprovechar al máximo los recursos con los que se cuenta.

A continuación, se mostrará el grafico 1, en el cual se evidencia el valor de la inversión extranjera desde 2012 a 2016 y a qué sector de la economía pertenece. De esta manera, es posible ampliar la aproximación a lo que ha sucedido en Colombia durante ese período.

Aunque se nota una disminución en la tendencia del año 2015, en 2016, se reactiva la inversión extranjera directa con un aumento del 36,6\% en octubre, con respecto al mismo mes de octubre del año anterior. Cabe anotar que se espera que esta se sostenga mediante las conversaciones con multinacionales o empresas trasnacionales que muestren interés en los sectores económicos en los que se está trabajando, así como a partir de la captación de inversión extranjera directa con la compra de acciones en compañías nacionales o la creación de subsedes de empresas en Colombia.

Procolombia es una de las entidades dispuesta a dar asesoría, capacitación y ayuda en los acercamientos o en las conversaciones con inversionistas para que 
Gráfico 1. Flujo de IED en Colombia por sector en 2012-2016 (US\$ millones)

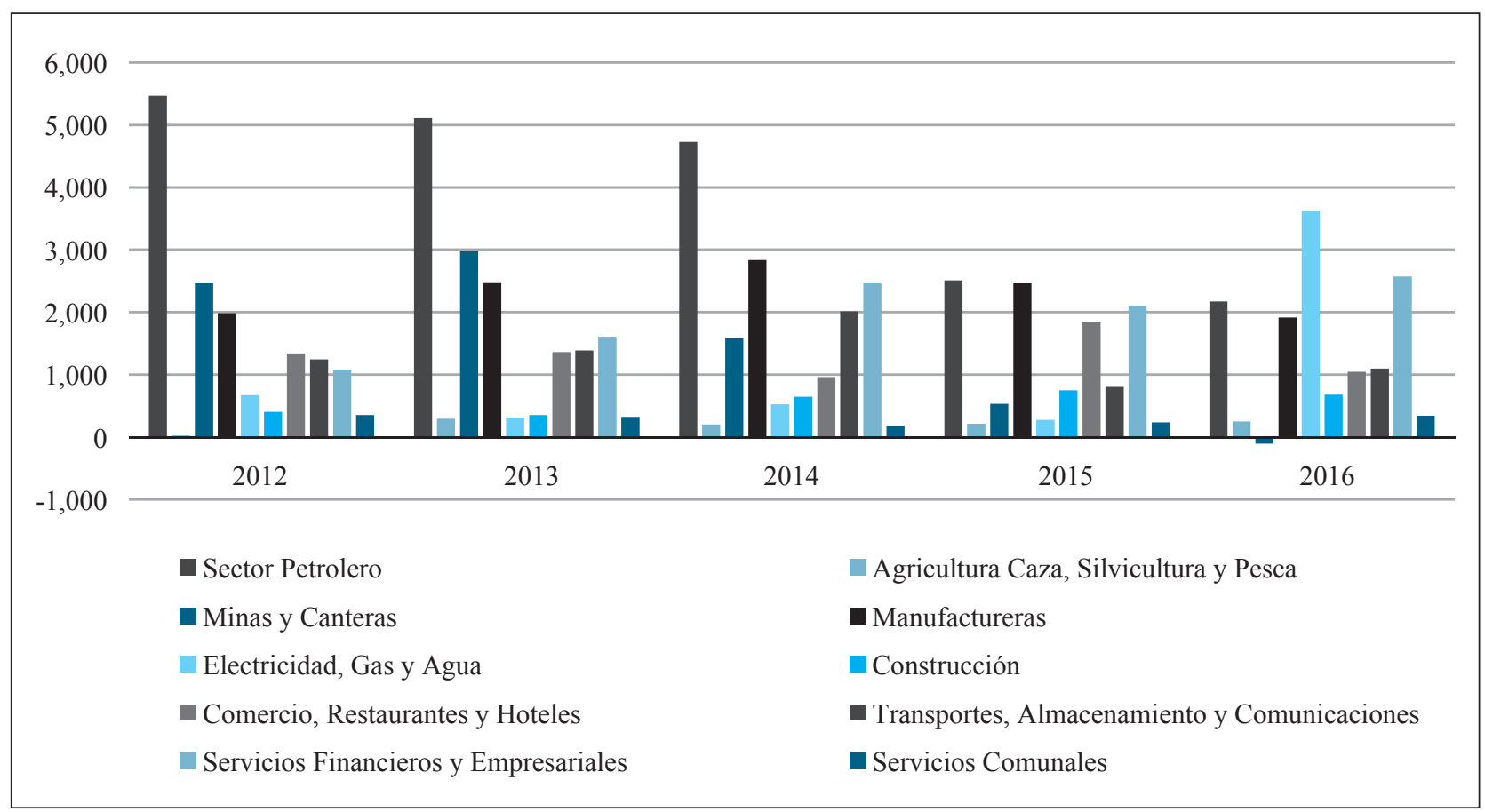

Fuente: Banco de la Republica de Colombia (2017). Elaboración propia.

se lleven a cabo este tipo de negociaciones. Su labor, finalmente, tiene un impacto en la creación de empleos, en los ingresos de recursos al mercado nacional, en recursos tecnológicos y en un intercambio de conocimientos que generan que la economía colombiana sea más atractiva para el mercado global.

Ahora, se debe anotar que el impacto que los flujos de inversión extranjera directa pueden tener en la economía colombiana depende de las ganancias que el inversionista pueda obtener y cómo ello permita acumular un capital en el país, lo que fomenta un escenario atractivo para otros inversionistas. También, está determinado el impacto por cómo afecta al sector económico en que se realiza dicha inversión, si se ve reflejada en la rentabilidad de la actividad económica del país. En este marco, no se trata de acabar con los recursos naturales del país, puesto que este no es el fin que se persigue. Más bien, se trata de encontrar el punto de equilibrio en que tanto el inversionista como la economía del país se vean beneficiados, es decir, que ambos ganen.

Dicho beneficio debe ser sostenible en el tiempo. En otras palabras, se alude a relaciones comerciales concebidas a largo plazo con la vista fija en generar estabilidad económica e incremento de nuestra balanza comercial como país exportador. Esto genera un ambiente de intercambio de conocimiento y desarrollo tecnológico que permite crear vínculos comerciales, como plantean Becerra Rodríguez et al. (2013), y Fernández (2014) en su investigación. 


\subsection{Análisis descriptivo del sector de la economía colombiana: Beneficio a flujos de inversión extranjera directa en Colombia}

\subsubsection{Sector hidroeléctrico de la economía colombiana}

En la actualidad, la economía colombiana ha diversificado los sectores económicos en los cuales se puede realizar la inversión extranjera directa, a partir de lo cual se han generado mayores ingresos a la economía. Esto ha sido de gran ayuda para el fortalecimiento de los mismos, debido que no solo se producen materias primas, sino que existe la posibilidad de transformarlas e innovar sacando el máximo provecho de ellas. Además, se han incluido servicios que se han ido desarrollando como parte de los beneficios de la inversión en el país; de este modo, se ha ampliado el portafolio de posibilidades. En la siguiente tabla, se presentan los sectores más destacados.

Tabla 2. Sectores económicos en Colombia

\begin{tabular}{|l|l|}
\hline Petróleo & Construcción \\
\hline $\begin{array}{l}\text { Agricultura, Caza, } \\
\text { Silvicultura y Pesca }\end{array}$ & Comercio, Restaurante y Hoteles \\
\hline $\begin{array}{l}\text { Minas y Canteras } \\
\text { (incluye carbón) }\end{array}$ & $\begin{array}{l}\text { Transporte, Almacenamientos y Comu- } \\
\text { nicaciones }\end{array}$ \\
\hline Manufactureras & $\begin{array}{l}\text { Servicios Financieros y Empresariales } \\
\text { (comprende las actividades auxiliares de la } \\
\text { intermediación financiera y las actividades } \\
\text { inmobiliarias, empresariales y de alquiler) }\end{array}$ \\
\hline $\begin{array}{l}\text { Electricidad, } \\
\text { Gas y Agua } \\
\text { (hidroeléctricas) }\end{array}$ & Servicios Comunales \\
\hline
\end{tabular}

Fuente: Procolombia (2017c). Elaboración propia.

Esta investigación se concentra en el sector de Electricidad, Gas y Agua; especialmente, las hidroeléctricas, que, en estos tiempos, han tomado tanta relevancia para las empresas que desean realizar flujos de inversión extranjera directa que se vean reflejados en la economía del país. Ejemplo de esto es la venta de Isagen, una de las empresas nacionales de origen estatal, que produjo tanta controversia el ańo pasado en el sector hidroeléctrico. Dicha compañía fue adquirida por otra empresa canadiense. Más adelante, se observarán los efectos que esto causa en la economía del país.

La generación de energía en el país puede ser hidráulica o térmica (solar y eólica). La primera consiste en la utilización de fuentes primarias hidráulicas, como ríos y lagos, que se conocen como filos de agua o cascadas. Para la segunda, se hace uso de calderas industriales, que funcionan con el uso de gas, diésel o carbón térmico, y mediante procesos térmicos de sistemas de producción energética. Entre dichos procesos, se encuentran la generación, que se refiere a las empresas que se solo generan energía para comercializarla; la autogeneración, que supone que las empresas producen energía para consumo propio; y la cogeneración, que es el resultado de un proceso productivo de la empresa. Esta última es una ingeniosa operación de la empresa, que la hace sustentable.

El sector hidroeléctrico en Colombia está compuesto principalmente por la generación de energía hidráulica, con un $66 \%$, y generación térmica, que corresponde a un 33\%. Durante el año 2015, la generación total de energía eléctrica fue de 66 548,66 GWh (gigavatio por hora). La generación de energía hidráulica representa un $63,8 \%$; mientras que las plantas térmicas, un $31 \%$. Por su parte, las plantas menores - que incluyen la planta eólica de Jepírachi (desarrollo de nueva generación de energía) - y la cogeneración aportan un $5,2 \%$ en cuanto a la producción de años anteriores.

El mercado de energía eléctrica en Colombia se crea a partir de la Constitución de 1991, y se establece con la Ley 142, Ley de Servicios Públicos Domiciliarios, y la Ley 143, Ley Eléctrica (Congreso de Colombia, 2011). Con estas dos leyes vigentes, se forman las bases para 
lo que con el tiempo se convertiría en el mercado del sector energético. Si bien el sector energético ya había nacido en Colombia en 1890, con la llegada de la energía, no se había institucionalizado y formalizado como tal el mercado de energía de manera organizada. Todos estos esfuerzos se han realizado con el fin de garantizar la demanda nacional del consumo interno. Al mismo tiempo, se ha creado un mercado mayorista que permite generar la opción de competencia sana. Es decir, se trata de un espacio en que el beneficiado finalmente es el usuario, que cuenta con energía adecuada para el uso que le vaya a dar, ya sea doméstica e industrial, y la encuentra a precios justos; en ese sentido, no se trata de un monopolio, sino de un servicio asequible para todos.

En las últimas décadas, el sector energético ha incrementado su participación en el PIB, con lo cual ha revelado que es uno de los sectores pilares. Por tal motivo, mediante la Ley 1450/2011 del Plan Nacional de Desarrollo, el gobierno espera ejecutar una serie de proyectos - que se encuentran en proceso- para fortalecer e incrementar la economía de Colombia. Esta medida permitirá la generación de nuevos empleos directos e indirectos, lo que, a su vez, facilita la disminución de los índices de pobreza, cuyos efectos se verán reflejados en la reducción de estos indicadores económicos y en el fortalecimiento de los mismos, como se tiene presupuestado.

La producción de energía de las hidroeléctricas en Colombia proviene de fuentes primarias. Esto la hace más atractiva en el momento, debido a que la negociación de este tipo de fuentes tiene un carácter de duración indeterminado, en la medida que los productos primarios son renovables. De este modo, en el momento de negociar una exportación de materia prima o de vender una empresa para capitalizar este recurso, es posible que se pueda generar flujo de inversión extranjera al permitir que participen empresas internacionales mediante la compra de sus acciones.

En comparación con el comportamiento económico, el desempeño de la demanda de energía eléctrica está proporcionalmente relacionado con la variable económica, lo que hace que se confirme la importancia que este sector tiene para la economía de Colombia y que la energía es un insumo productivo. En resumen, existe una relación entre la demanda de energía eléctrica y el PIB dentro de un mismo período, como lo veremos en el siguiente gráfico.

Gráfico 2. Comportamiento de variación del PIB y el sector hidroeléctrico 2012-2016

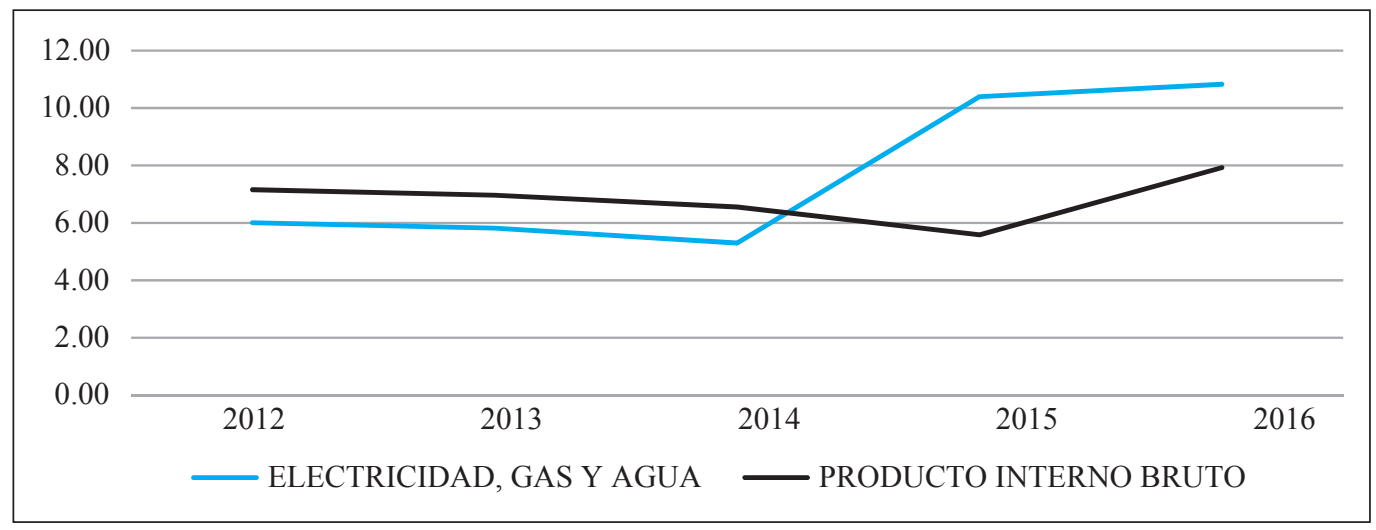

Fuente: Perfetti del Corral, Prada Lombo y Buitrago Hoyos (2017) . Elaboración propia. 
Como se puede observar en el gráfico anterior, la economía de Colombia y su PIB (excepto entre los años 2014 y 2016) se encuentran estrechamente relacionados con la demanda interna y la producción de las hidroeléctricas colombianas. De esta manera, queda claro que es uno de los sectores económicos más productivos del país, y que tiene mayor influencia en la gestión y el progreso económico. Por eso, el Gobierno — desde la presidencia- con el Ministerio de Minas y Energía, y el Ministerio de Comercio Exterior se ha enfocado en este sector y se han propuesto el desarrollo del mismo. Su acción se realiza en conjunto con otras entidades gubernamentales, como la Unidad de Planeación Minero-Energética, que tiene un portafolio que ofrece este servicio como una de las mejores inversiones que una empresa extranjera podría adquirir.

A continuación, en la tabla 3, se mencionan las principales hidroeléctricas colombianas y dónde se encuentran ubicadas.

\section{Tabla 3. Principales hidroeléctricas colombianas y su departamento}

\begin{tabular}{|l|l|}
\hline Central hidroeléctrica en el país & \multicolumn{1}{|c|}{ Departamento } \\
\hline Central Hidroeléctrica Miel I & Caldas \\
\hline Central hidroeléctrica de Chivor & Boyacá \\
\hline Central hidroeléctrica del Guavio & Cundinamarca \\
\hline Represa Urrá I & Córdoba \\
\hline Hidroeléctrica de Sogamoso & Santander \\
\hline Hidroituango & Antioquia, en construcción \\
\hline Central hidroeléctrica San Carlos & Antioquia \\
\hline
\end{tabular}

Fuente: Hernández Torres (2011). Elaboración propia.

En relación con la demanda interna en Colombia, esta es de $66548,66 \mathrm{GWh}$, con lo cual se registra un crecimiento del 5,5\%, con respecto al año anterior. El gráfico 3 contiene información sobre la demanda nacional interna de energía desde el año 2005 hasta el año 2015, en que se refleja el constante crecimiento de la demanda energética en el país en gigavatios.

Las hidroeléctricas resultan de vital importancia para todo el proceso de producción del país, en cualquiera de sus modalidades, debido a que es por medio de la energía que se desarrolla el funcionamiento tanto industrial como comercial del país. A partir de ello, es posible la aceleración de los procesos, lo que genera que las empresas sean más eficientes. En ese sentido, podríamos decir que el sector energético es el sector con mayor influencia para el desarrollo de los demás sectores y, de paso, para la economía del país. Por eso, es trascendental tener una proyección clara de la generación de esta para los venideros años. En años anteriores, por problemas de proyección, Colombia ha tenido inconvenientes con los diferentes fenómenos naturales. Principalmente, las sequías llevaron a realizar racionamientos que han afectado a todos los sectores del país, entre ellos, el sector empresarial, en que se hace imprescindible el uso energético para el funcionamiento a nivel industrial para la producción, las operaciones e incluso los procesos administrativos.

El sector energético colombiano desempeña un papel muy importante en la economía, lo que se refleja en los datos: en el año 2014, el 10\% del PIB estaba representado por este sector; el IED obtuvo el $43 \%$ en el sector energético, y sumó el $70 \%$ de las exportaciones entre minas y energías del país. El año anterior (2013), las regalías obtenidas por impuestos generados de este sector representaron un 31\% para el Estado, además de otro tipo de transacciones realizadas.

Los tipos de transacciones que se manejan en el mercado nacional para la compra de energía producida por las hidroeléctricas del país son dos: contratos bilaterales y transacciones en bolsa. Los contratos bilaterales se deben ceñir al marco regulatorio establecido 
Gráfico 3. Comportamiento de la demanda de energía en Colombia

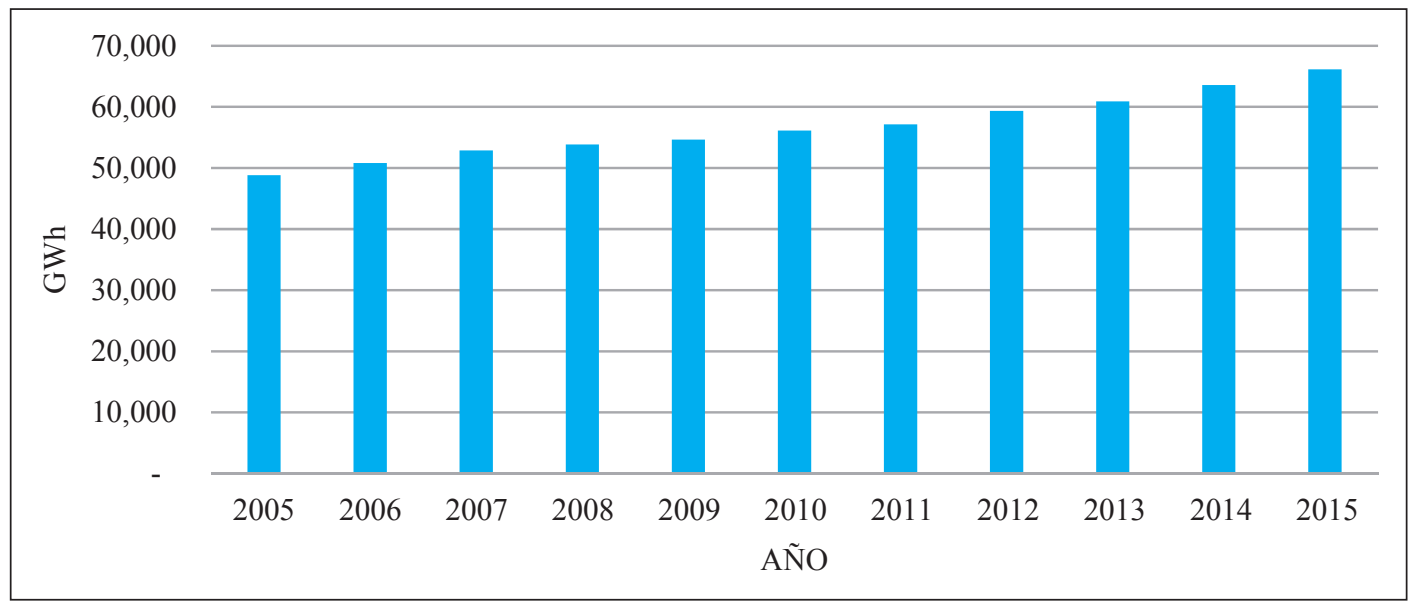

Fuente: Unidad de Planeación Minero-Energética - UPME (2016). Elaboración propia.

con el fin de proteger el libre mercado o la sana competencia. Estos son aplicados a los comercializadores y a los usuarios, y se deben registrar ante el Administrador del Sistema de Intercambios Comerciales (Asic). Cuando los contratos no están regulados, los precios son establecidos por las dos partes y se pacta un precio de manera libre. Los contratos bilaterales se transforman en una herramienta para los participantes enemigos al riesgo que prefieren establecer un acuerdo con anterioridad que exponerse al riesgo de la volatilidad de los precios de la bolsa de energía; así, se genera el precio por la fuerza de la oferta y la demanda de los factores del contrato. Las transacciones en bolsa son otro tipo de transacción que se efectúa en la bolsa de energía. En este caso, los generadores pertenecientes al mercado de energía mayorista realizan sus ofertas de precios en bolsa a las 8 de la mañana; este precio incluye la variación que pueda sufrir el costo en el trascurso de 24 horas y la disponibilidad del momento, además de incluir la variación de la prima del riesgo. En ese sentido, debe ser un estudio bien establecido. Las empresas que son generadoras de energía hidroeléctrica tienen la obligación de ańadir el costo equivalente de energía del cargo por capacidad (CEE), lo que asegura las condiciones de las plantas hidroeléctricas para tener la capacidad de cumplimiento en distintas situaciones, como puede ser en condiciones de sequía. Esto, al final, genera un impuesto que financia la cobertura en las zonas interconectadas, lo que ha ayudado a fortalecer la infraestructura energética del país. De este modo, se favorece la economía del país, en la medida que existe mayor cobertura de este servicio primario que se garantiza en todos los sectores.

\section{Análisis de medición de datos del flujo de inversión}

\subsection{Relevancia del sector hidroeléctrico en el crecimiento de la economía colombiana}

El sector hidroeléctrico ha recibido durante los últimos años un fuerte aporte por parte de los flujos de inversión extranjera (44\% del total de flujo de inversión). Esto ha generado un incremento en la economía 
colombiana de este sector en especial, en la medida que la economía colombiana se ha convertido en un gran atractivo para los inversionistas. En este contexto, la abundancia de sus recursos naturales, acompañada de una mano de obra barata y la tecnificación, es un factor determinante en el momento de invertir.

Los aspectos previamente mencionados son las causas de que la inversión en hidroeléctricas - tanto en Latinoamérica, a nivel general, como en Colombia específicamente - sea la tendencia de estos años. Los inversionistas extranjeros están en la búsqueda de mercados energéticos que les puedan mostrar un potencial de crecimiento y que estén dispuestos a la explotación de los recursos hidroeléctricos, a partir de lo cual se genera una perspectiva de crecimiento. Aunque existe aún un vacío en cuanto a la tecnificación e innovación en los procesos, Colombia cuenta con más recursos que la convierten en un buen espacio para la inversión.

La relevancia del sector hidroeléctrico como motor del desarrollo económico en Colombia se ve reflejada al observar el PIB, que, de 2006 a 2009, fue de 9,7\%; durante el período 2010 a 2013, de 11,2\%; y de 2014 a 2016 , de $13,43 \%$, con lo cual se evidencia que ha sido el desarrollo del sector. Esto, en parte, se debe a los flujos de inversión extranjera directa, los que, para 2018 , crecerán a una escala del $46 \%$, de acuerdo con el Plan de Desarrollos de 2014 a 2018 (Departamento Nacional de Planeación, 2014).

Los sectores mineros e hidroeléctricos cuentan con regímenes especiales para los flujos de inversión directa, pero estos inversionistas deben estar suscritos a la Superintendencia de Sociedades de la Cámara de Comercio del departamento que corresponda, al igual que de industria y comercio. Adicionalmente, deben contar con las concesiones para poder participar en las actividades de dicho sector. Sin embargo, se debe tener claro que existe un límite de inversión extranjera directa permitido, por lo cual existe un sistema legal y regulatorio en Colombia ceńido a normas internacionales. A través de esta medida, se pretende buscar la trasparencia del mercado y la libre competencia de empresas nacionales e internacionales (Rothbard, 2012).

Entre los esfuerzos que ha realizado el gobierno, destaca la creación de Procolombia, fundada en noviembre de 1992. Esta agencia se encarga de promover todo el comercio internacional; por medio de esta agencia, se crean los acercamientos entre empresarios y se presta asistencia a los empresarios extranjeros que están interesados en invertir en sectores económicos colombianos por medio de servicios especializados. Adicionalmente, Procolombia se encarga de crear alianzas entre los empresarios nacionales y los empresarios internacionales, de instituciones tanto públicas como privadas, que apoyan iniciativas de negocios o en el fortalecimiento del desarrollo tecnológico. Sin embargo, cabe anotar que Procolombia no promociona los bienes y servicios del país; solo se limita a realizar acercamientos, seguimientos y acompañamiento en los procesos de los empresarios para que la economía del país se vea fortalecida (Pérez Pinzón, 2015).

Como decían Abbott, Cushman y de Vita (2012), el flujo de inversión extranjera sí genera un efecto positivo en los países que reciben estos tipos de inversión. Con respecto a ello, en el análisis de la relevancia económica de los flujos de inversión extranjera directa en el sector hidroeléctrico, se observa que estos se han concentrado en cincos áreas principales: balanza de pagos, esfuerzo de inversión, productividad, empleo y desarrollo económico.

Las consecuencias del ingreso de las multinacionales pueden ser directas o indirectas; dichas multinacionales afectan a muchas empresas de diversos sectores 
de la economía colombiana. La inversión en su totalidad y el tipo de la misma son factores de importancia al momento de considerar la relevancia que la inversión tiene para la economía. En el año 2016, la inversión extranjera directa en Colombia ascendió a US\$ 13 593, un 15,86\% más que durante el año anterior; por el contario, en el sector hidroeléctrico, durante 2016, dicha inversión correspondió a US\$ 1914 , lo que representa un $-22,54 \%$, en comparación con el año anterior. A continuación, en el gráfico 4, se presenta la comparación entre el total de flujo de inversión extranjera directa, y la inversión del sector hidroeléctrico entre 2012 y 2016.

A mayor desarrollo de proyectos en el sector hidroeléctrico, habrá un mayor incremento del capital bruto, lo que se verá reflejado en la generación de empleos y la inversión en sectores secundarios. Esto, a su vez, repercutirá en una mayor apertura económica, que también se evidenciará en el aumento del volumen de las exportaciones y, por ende, en la balanza de pagos para la economía colombiana.

Uno de los objetivos trazados más importantes a desarrollar en las políticas de las hidroeléctricas de Colombia es la implementación de un plan con el objetivo de promover al máximo el aprovechamiento sostenible de los recursos naturales, tanto los renovables como los no renovables. Se debe, también, crear estrategias que permitan mejorar la cobertura y la calidad de los servicios domiciliarios e industriales, puesto que la finalidad de la recepción de la inversión extranjera directa no es solo crear un beneficio para el inversionista; se debe obtener un beneficio de este tipo de inversiones. Se recibe dinero, tecnología e innovación para generar y fomentar el mejoramiento de los servicios públicos y, en ocasiones, hasta los servicios privados; esto, a su vez, permite que mejore el nivel de vida de la población colombiana, en especial, de los menos beneficiados o de las regiones más apartadas del país.

Gráfico 4. Comparación de IED total con el sector hidroeléctrica 2012-2016 (en US\$ millones)

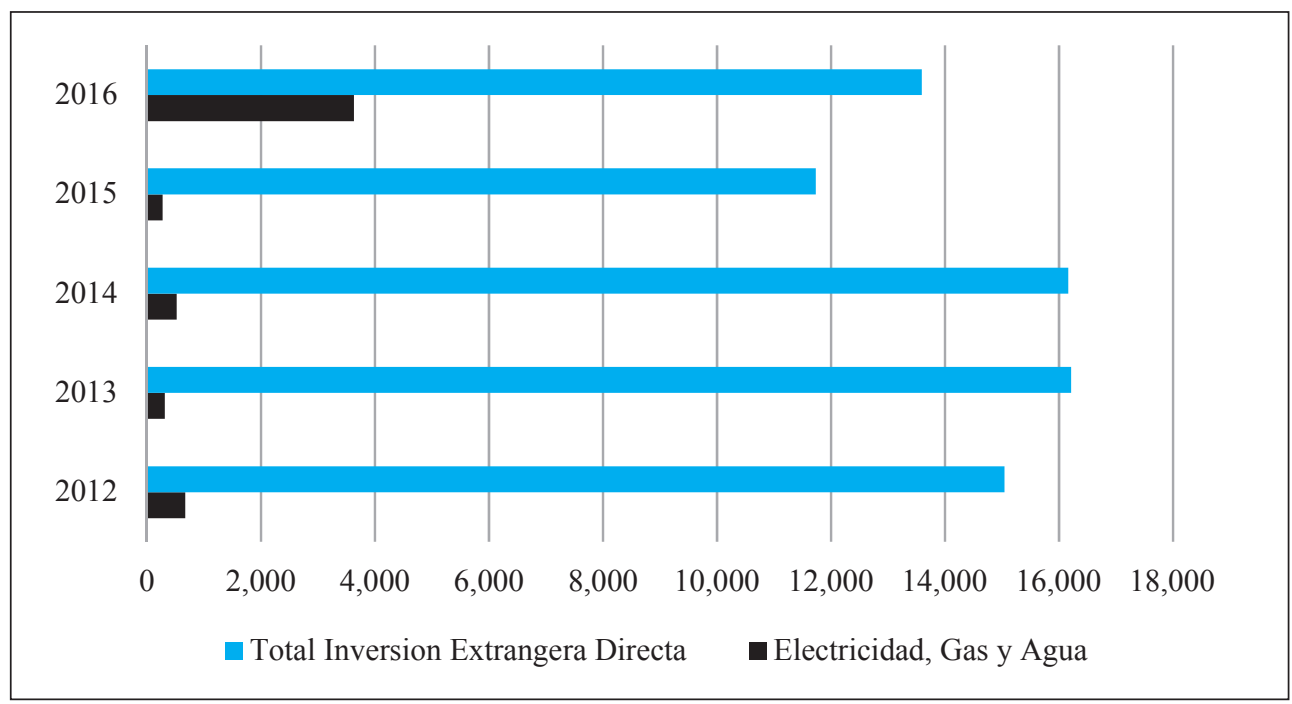

Fuente: Unidad de Planeación Minero Energética - UPME (2016). Elaboración propia. 
En mayo de 2015, Colombia suscribió la carta internacional de las energías en el marco de la Conferencia Ministerial de La Haya; este tipo de declaraciones encierra unos principios comunes y estándares para el buen manejo y gobierno del sector energético en Colombia. Esta carta internacional de la energía comprende como uno de sus principales objetivos el fortalecimiento y la cooperación con más de setenta países signatarios de todas partes de los diferentes continentes y organizaciones internacionales, que incluyen —entre otras - a la Unión Europea y a la comunidad económica de los Estados de África de Occidente. Hasta el momento, de Latinoamérica, solo han firmado esta declaración política Chile y Colombia, que se han convertido - a la vez- en países observadores del cumplimiento de lo que está establecido en dicha carta. Por consiguiente, Colombia se ha convertido en un destino para la inversión extranjera directa en hidroeléctricas, puesto que no solo cuenta con la mejor infraestructura energética de la región, sino con otras ventajas en el mercado hidroeléctrico.

El país tiene una legislación especial que establece la institucionalidad, que consta de dos reformas (Ley 142 y Ley 143 del año 1994), a partir de las cuales se generan las garantías para el sector, así como para los inversionistas extranjeros que consideren realizar su inversión en Colombia. Al final, esto se traduce en una regulación en las normas del mercado en cuanto a la propiedad, y, posteriormente, en lo que respecta a la generación y la distribución de los recursos hidroeléctricos. De esta manera, se beneficia a la economía del país y se ayuda a la generación de proyectos de desarrollo hidroeléctrico.

El sistema hidroeléctrico del país está en la capacidad desarrollar energía, que representa el 66,3\% de la participación neta, según el Sistema Interconectado Nacional (2013). También, se cuenta con recursos térmicos, que corresponden al 28,9\%, así como otros cogeneradores menores, que contribuyen con un $4,8 \%$. Dichos recursos pueden responder tanto al consumo interno como a la energía que se piensa exportar, lo que genera más ingresos a la balanza comercial del país.

Adicionalmente, la generación de energía en Colombia, en su mayoría perteneciente al sector hidroeléctrico, tan solo en el año 2015 logró una producción de 42 463,8 GWh. Por otra parte, cuenta con una generación de energía térmica de 20 631,2 GWh, mientras que el aporte de los generadores menores y los cogeneradores es de 3453,5 GWh, lo que se traduce en una buena respuesta para los proyectos de inversionistas.

Las hidroeléctricas en Colombia han provisto un suministro de energía, que, en cuanto a crecimiento, corresponde a un promedio anual de 3,2\%. Dicha cifra evidencia un aumento durante los últimos seis años: entre 2010 y 2015, el promedio de energía fue de 1,7\%; para el año 2015, el sector hidroeléctrico alcanzó su segundo mejor crecimiento de demanda energética en los últimos diez años (un 4,25\%) y el consumo fue de $66174 \mathrm{GWh}$.

Para 2015, la industria de la manufactura en Colombia se convirtió en uno de los sectores con más demanda de este producto, con un consumo de 9941 GWh. De igual manera, el sector de Minas y Canteras, para la explotación, consumió 4637 GWh, mientras que, en el caso de otros sectores - como servicio sociales, comunales y personales- fue de 1809 GWh. Se trata, entonces, de una alta demanda solo en consumo interno para la generación económica del país. En ese sentido, es un sector con mucha proyección, aun con muchas áreas por desarrollar y estudiar, como la manera de generar energía por otros medios. 
Como se expresó previamente en este documento, es un sector motor de la economía colombiana, que merece relevancia y eso lo muestra el interés que en los últimos años se ha mostrado hacia él: tiene la capacidad efectiva neta instalada del Sistema Interconectado Nacional (SIN) de 16420 MW (megavatios). En ese marco, es importante reafirmar las condiciones y las cualidades del sector para que se continúe la dinámica de inversión.

A continuación, se presentan las empresas -y el detalle de los países de los que provienen - que han realizado flujos de inversión extranjera directa en el sector hidroeléctrico en Colombia:

- Endesa: Es la sucursal del grupo Enel, de origen español, que consiguió la participación de la empresa de generación Emgesa y Betania con una capacidad instalada de 2895 MW.

- Unión Fenosa: Es una empresa de origen español que adquirió a Electricaribe y Electricosta, a partir de lo cual se convirtió en la mayor distribuidora y comercializadora de energía en la costa norte colombiana. Cabe anotar que esta empresa no ha tenido tan buenos resultados.

- AES: Es una sucursal en Colombia de AES (Corporation Applied Energy Services), originaria de Estados Universo.

- Chivor: Es una de las empresas más grandes del país, que tiene la capacidad de generar $1000 \mathrm{MW}$ de su capacidad instalada.

- Steag: Esta empresa, originaria de Alemania, tiene una planta térmica de carbón de bajo grado de nombre Termopaipa, que se encuentra en Paila. Esta fue la primera planta de energía en el exterior, planeada, financiada y construida por la empresa Steag.

- Brookfield Asset Management (BAM): Fue la empresa canadiense que adquirió el 57,6\% de la generadora de energía hidroeléctrica Isagen.
En el gráfico 5, se muestra el porcentaje de la inversión de acuerdo con el país de origen.

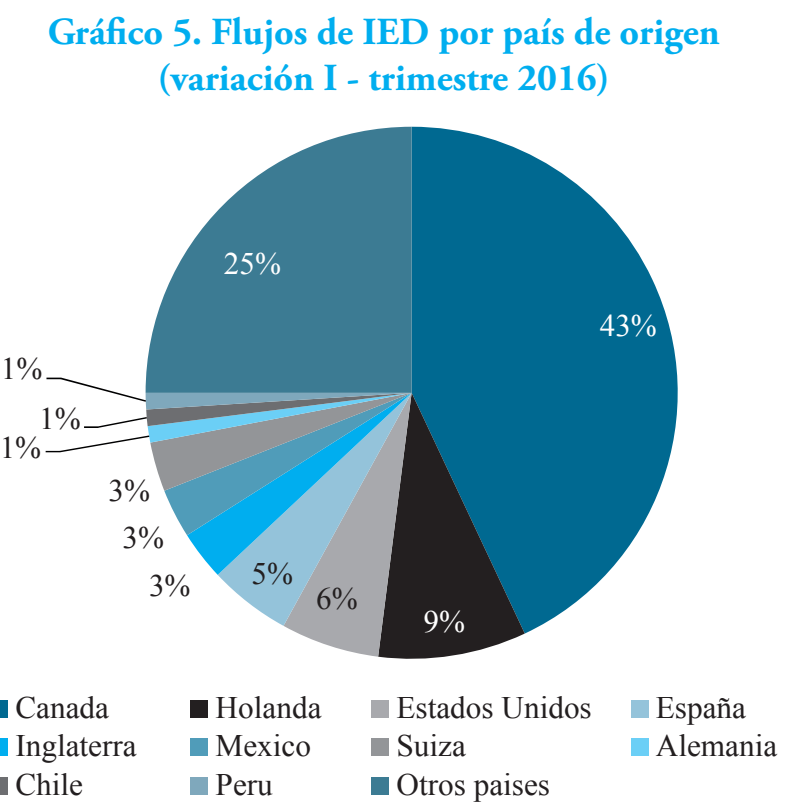

Fuente: Procolombia (2017a, 2017b). Elaboración propia.

En este documento, se ha observado tanto las ventajas de las empresas interesadas en realizar inversión extranjera directa en el sector de hidrocarburos como también las ventajas que Colombia — como paíspuede ofrecer. Contamos con un marco legislativo que ofrece las garantías para los inversionistas, las zonas francas especializadas para el desarrollo del mercado, los beneficios dados por el gobierno, las ventajas competitivas y comparativas — que se ven reflejadas en la infraestructura y el desarrollo para el funcionamiento del sector-. Además, en los últimos años, se ha fomentado el esfuerzo en innovación y tecnología, a lo que se suma la abundancia con la que en el momento se cuenta en lo que respecta a recursos hídricos para las hidroeléctricas. En síntesis, Colombia cuenta con fuentes altamente renovables, con una economía en crecimiento y el sector hidroeléctrico como el sector 
con más relevancia para el crecimiento económico del país (Ávila-Foucat, 2017).

Esto predispone el camino para un futuro de excelentes posibilidades para todos los actores implicados en el sector. En ese sentido, hay que confiar en el fortalecimiento del sector y en los esfuerzos realizados por el gobierno con sus diferentes actores implicados para que se dé la relevancia del sector hidroeléctrico en la economía colombiana y se produzcan más inversiones para las hidroeléctricas en función del mismo mejoramiento de la prestación de este servicio. No debemos olvidar que toda negociación de recursos primarios será una excelente inversión a futuro, como lo ha mencionado Castro (2012).

\section{Conclusiones}

Para finalizar, cabe resaltar que la recepción de inversión extranjera directa traerá efectos positivos en la economía colombiana, como lo han planteado otras investigaciones (Lascurain Fernández y López González, 2013). A partir de ello, los sectores económicos pueden desarrollarse e innovar en lo que respecta a la producción de materias primas transformadas, lo que genera un valor agregado a la producción. De este modo, es posible facilitar la creación de empresas o la estimulación de las ya existentes en el país; esto, a su vez, permite que se fomenten empleos directos e indirectos, e incentiva la circulación de dinero (Gil, López y Espinosa, 2013).

También, a partir del PIB como indicador económico de la economía en Colombia, se aprecia la influencia que tienen los flujos de inversión extranjera directa, los que dan la sensación de una economía más estable, como lo indica Padilla Sierra (2015), sobre todo en los sectores en los que esta influye. De esta manera, se incentiva la inversión de otros inversionistas extranjeros y se reafirma la economía del país.

\section{Recomendaciones}

Debido a que los flujos de inversión extranjera tienen tanta relevancia para la economía colombiana, se deben buscar las estrategias que faciliten incentivar la generación de más inversión —como lo indican Concha y Gómez (2016) en su investigación- no solo en el sector hidroeléctrico, sino en otros sectores que también pueden tener relevancia. Las instancias gubernamentales podría promover esa inversión, por medio de beneficios tributarios, a aquellas multinacionales o inversionistas que deseen trasladar su dinero hacia Colombia, y, así, fomentar el desarrollo económico (Lasarte Navamuel y Pérez Rivero, 2015).

Las empresas multinacionales o trasnacionales que realizan movimientos de inversión extranjera directa pueden ayudar en el contexto actual —en que se desarrolla el proceso posconflicto- al fomentar que un porcentaje o un número determinado de trabajadores sean personas que estén en un proceso de reinserción a la vida civil. De esta manera, se contribuye en materia de responsabilidad social empresarial, un aspecto tan importante en la actualidad.

Aunque los flujos de inversión extranjera directa son relevantes para la economía colombiana, cabe destacar que los recursos hidroeléctricos no son de generación perpetua, por lo cual es necesario un estudio tanto de la demanda interna del país como de la demanda que el inversionista considera exportar con el objetivo de determinar cuál es la producción hidroeléctrica requerida. A partir de ello, será posible saber si se puede cumplir y, a su vez, desarrollar un plan que permita que este recurso sea bien conservado para que no se extinga por el abuso de las compañías.

Por último, es necesario realizar un seguimiento a las empresas que crean o reciben inversión extranjera directa con el fin de evaluar cuál es su comportamiento 
en la economía del país. De este modo, en caso la empresa muestre un descenso, es posible saber cuál es el motivo y plantear de qué manera se puede brindar apoyo, ya sea con mano de obra más capacitada, innovación tecnológica u otro (Leiva, Alegre y Monge, 2014). A través de una medida como esta, es posible no dejar escapar este tipo de inversión y evitar un posible decaimiento de la economía.

\section{Referencias}

Abbott, Andrew, David O. Cushman y Glauco De Vita (2012). Exchange rate regimes and foreign direct investment flows to developing countries. Review of International Economics, 20(1), 95-107. https://doi. org/10.1111/j.1467-9396.2011.01010.x

Álvarez, Ana María (2016). Retos de América Latina: Agenda para el desarrollo sostenible y negociaciones del siglo XXI. Problemas del Desarrollo, 47(18), 9-30. https://doi.org/10.1016/j.rpd.2016.08.002

Ávila-Foucat, Sophie (2017). Desafíos del sector primario y políticas públicas sustentables. Economía Informa, 402, 29-39. https://doi.org/10.1016/j.ecin.2017.01.003

Banco de la República de Colombia (2017a). Flujos de inversión directa. Balanza de pagos. Banrep.gov. Recuperado el 22 de noviembre de 2017 de http://www. banrep.gov.co/es/inversion-directa

Banco de la República de Colombia (2017b). Régimen de inversiones internacionales. Preguntas frecuentes y casos prácticos. S/l: Banco de la República de Colombia, Departamento de Cambios Internacionales. Recuperado el 21 de noviembre de 2017 de http://www.banrep.gov.co/ docum/Lectura_finanzas/pdf/reg-inv-internal-017.pdf

Becerra Rodríguez, Fredy, Héctor Mauricio Serna Gómez y Julia Clemencia Naranjo Valencia (2013). Redes empresariales locales, investigación y desarrollo e innovación en la empresa. Cluster de herramientas de Caldas, Colombia. Estudios Gerenciales, 29(127), 247257. https://doi.org/10.1016/j.estger.2013.05.013
Blanco Rangel, Ibelis (2013). La apropiación social de la ciencia, la tecnología y la innovación y los organismos de cooperación internacional. El Ágora USB, 13(2), 179-189. https://doi.org/10.21500/16578031.88

Castro, Lucio (2012). Variedades de primarización, recursos naturales y diferenciación: El desafío de Sudamérica en la relación con China. Apuntes, 39(259), 61-98. https://doi.org/10.21678/apuntes.71.661

Chonchol, Jacques (1998). Impacto de la globalizacion en las sociedades latinoamericanas: ¿qué hacer frente a ello? Estudos Avançados, 12(34), 163-186. https://doi. org/10.1590/S0103-40141998000300020

Concha, José Roberto y Oscar Alberto Gómez (2016). Análisis de atracción de inversión extranjera a países de la Alianza del Pacífico. Estudios Gerenciales, 32(141), 369-380. https://doi.org/10.1016/j.estger.2016.11.001

Congreso de Colombia (2011). Normas y Leyes de Servicios Públicos Domiciliarios. Secretaría Jurídica Distrital. Recuperado el 22 de noviembre de 2017 de http://www.alcaldiabogota.gov.co/sisjur/normas/ Norma1.jsp?i=4631

Contreras-Pacheco, Orlando E., Aura Cecilia Pedraza Avella y Mauricio José Martínez Pérez (2017). La inversión de impacto como medio de impulso al desarrollo sostenible: Una aproximación multicaso a nivel de empresa en Colombia. Estudios Gerenciales, 33(142), 13-23 https://doi.org/10.1016/j.estger.2017.02.002

Corbella, Virginia y Karla Sarmento G. de Souza (2017). La integración comercial y productiva de Aladi y su cambio estructural. Economía UNAM, 14(41), 90-109. https://doi.org/10.1016/j.eunam.2017.06.005

Cordera Campos, Rolando (2014). Más allá de la crisis: Al rescate del desarrollo. Economía UNAM, 11(31), 3-24. https://doi.org/10.1016/s1665-952x(14)70443-8

Departamento Administrativo Nacional de Estadística (DANE) (2017). Cuentas trimestrales - Colombia Producto Interno Bruto (PIB) Segundo Trimestre de 
2017 Contenido. Boletín Técnico. Comunicación Informativa DANE, 26. Recuperado el 22 de noviembre de 2017 de http://www.dane.gov.co/files/investigaciones/ boletines/pib/bol_PIB_IItrim17_oferta_demanda.pdf

Departamento Nacional de Planeación, República de Colombia (2014). Bases del Plan Nacional de Desarrollo. Versión preliminar para discusión de Consejo Nacional de Planeación. S/l: Departamento Nacional de Planeación. Recuperado el 21 de noviembre de 2017 de http://www. urosario.edu.co/observatorio-legislativo/Documentos/ Bases-Plan-Nacional-de-Desarrollo-2014-2018.pdf

Desbordes, Rodolphe y Shang-Jin Wei (2017). The effects of financial development on foreign direct investment. Journal of Development Economics, 127(c), 153-168.

Díaz Castro, Santiago (2013). Incidencia del nuevo régimen de precios de transferencia en los contratos de colaboración empresarial en Colombia. Revista de Derecho Privado, 50, 2-18. https://doi.org/10.15425/ redepriv.50.2013.06

Escandón Barbosa, Diana y Andrea Hurtado Ayala (2014). Factores que influyen en el desarrollo exportador de las pymes en Colombia. Estudios Gerenciales, 30(131), 172-183. https://doi.org/10.1016/j.estger.2014.04.006

Fernández, Rick (2013). It takes two to tango: Commercial relation beyond of bilateral agreement, China and Colombia to sign a free trade agreement. American Journal of Business and Management, 2(4), 275-295.

Fernández, Rick (2014). Empirical result on firms' cluster integration: Should firms evolve beyond their region?. International Journal of Trade, Economics and Finance, 5(3), 204-211. https://doi.org/10.7763/ijtef.2014. v5.372

Fuentes Soriano, Maria Isabel, Jose Manuel Ruiz-Giardín y Jesus Sanz (2006). Paludismo: un diagnóstico emergente. Estudio descriptivo de 25 casos. Revista Clínica Española, 206(10), 491-494. https://doi.org/10.1016/ s0014-2565(06)72874-0
Gálvez Albarracín, Edgar Julián y Domingo García Pérez de Lema (2012). Impacto de la innovación sobre el rendimiento de la mipyme: Un estudio empírico en Colombia. Estudios Gerenciales, 28(122), 11-27. https://doi.org/10.1016/s0123-5923(12)70191-2

Garavito, Aarón, Ana María Iregui y María Teresa Ramírez (2014). An empirical examination of the determinants of foreign direct investment: A firm-level analysis for the Colombian economy. Revista de Economía Del Rosario. 17(1), 5-31. https://doi.org/10.12804/rev.econ. rosario.17.01.2014.01

García-Pérez de Lema, Domingo, Edgar Julián GálvezAlbarracín y Gonzalo Maldonado-Guzmán (2016). Efecto de la innovación en el crecimiento y el desempeño de las mipymes de la Alianza del Pacífico. Un estudio empírico. Estudios Gerenciales, 32(141), 326335. https://doi.org/10.1016/j.estger.2016.07.003

Gazol Sánchez, Antonio (2016). Libre comercio: Tratados y nuevo orden. Un balance. Economía UNAM, 13(38), 122-130. https://doi.org/10.1016/j.eunam. 2016.05.006

Gil, Edgar Ariel, Silvio Fernando López y Dorian Alonso Espinosa (2013). Factores determinantes de la inversión extranjera directa en América del Sur. Perfil de Coyuntura Económica, 22, 55-85.

Gómez Toro, Catalina (2014). La relación virtuosa de la seguridad y la inversión extranjera directa en Colombia (1994-2013). Ensayos de Politica Económica, 8(2), 62-87.

González Molina, Rodolfo Iván (2015). Venturas y desventuras de las actuales integraciones latinoamericanas. Economia Informa, 392, 65-95. https://doi.org/10.1016/j.ecin.2015.05.013

Green, Anne E. e Ilia Livanos (2015). Involuntary nonstandard employment and the economic crisis: Regional insights from the UK. Regional Studies, 49(7), 1223-1235. https://doi.org/10.1080/0034340 4.2013 .825712 
Gutiérrez Haces, María Teresa y Adelina Quintero (2016). Toward the construction of an international regime to protect foreign investment. Norteamérica, 11(2), 109-138. https://doi.org/10.20999/nam.2016.b005

Hernández Torres, Camilo Andres (2011). Análisis ambiental de las grandes centrales hidroeléctricas de Colombia aplicando metodología multiobjetivo. Tesis de licenciatura en Ingeniería Ambiental y Sanitaria. Bogotá: Universidad de La Salle, Facultad de Ingeniería. Recuperado el 22 de noviembre de 2017 de http://repository.lasalle.edu.co/bitstream/handle/10185/14037/T41.11 H430a.pdf?sequence $=2$

Lagos Cortes, Diógenes y Carlos Enrique Vecino Arenas (2014). Influencia del gobierno corporativo en el costo de capital proveniente de la emisión de deuda. Estudios Gerenciales, 30(130), 73-84. https://doi. org/10.1016/j.estger.2014.02.010

Lasarte Navamuel, Elena y José Luis Pérez Rivero (2015). Regímenes de tipo de cambio y crecimiento económico en países en desarrollo. Cuadernos de Economía, 38(106), 11-26. https://doi.org/10.1016/j. cesjef.2014.04.002

Lascurain Fernández, Mauricio y Jesús López González (2013). Retos y oportunidades de la globalización económica. Revista Confines, 9.

Leiva, Juan Carlos, Joaquín Alegre y Ricardo Monge (2014). Los emprendedores surgidos de las empresas multinacionales de inversión extranjera directa: Un estudio exploratorio en Costa Rica. Estudios Gerenciales, 30(131), 124-133. https://doi.org/10.1016/j. estger.2013.12.004

Levy Orlik, Noemi (2016). Política fiscal y desequilibrios económicos: El impacto de la composición del gasto público sobre el crecimiento de la economía mexicana. Economía UNAM, 13(39), 82-105. https://doi. org/10.1016/j.eunam.2016.08.004

Lim, Jamus y Sanket Mohapatra (2016). Quantitative easing and the post-crisis surge in financial flows to

developing countries. Journal of International Money and Finance, 68, 331-357. https://doi.org/10.1016/j. jimonfin.2016.02.009

Martínez-San Román, Valeriano, Marta Bengoa y Blanca Sánchez-Robles (2016). Foreign direct investment, trade integration and the home bias: Evidence from the European Union. Empirical Economics, 50(1), 197229. https://doi.org/10.1007/s00181-015-0942-y

Padilla Sierra, Alcides de Jeús (2015). Uso de variables de actividad economica en la estimacion del PIB per cápita microterritorial. Cuadernos de Economía, 34, 349-376. https://doi.org/10.15446/cuad.econ. v34n65.45936

Pérez Pinzón, Luis Rubén (2015). Caracterización de las fuentes de financiación para el sector turismo en Santander (Colombia). Turismo y Sociedad, 17(103). https://doi.org/10.18601/01207555.n17.06

Plaza Martínez, Ricardo (2014). Multiplicador monetario y dinero electrónico. Creación de dinero a partir de depósitos y efectivo electrónico. Cuadernos de Economia, 37(104), 125-130. https://doi.org/10.1016/j. cesjef.2013.07.002

Procolombia (2013). Estadisticas de inversión extranjera directa en Colombia - Flujos de inversión extranjera directa según balanza de pagos. Procolombia. Recuperado el 21 de noviembre de 2017. http://www. inviertaencolombia.com.co/IED_-_Cifras_I_trimestre_2016.pdf

Procolombia (2017a). Protección a la inversión extranjera. Invierta en Colombia, 13. Recuperado el 21 de noviembre de 2017 de http://www.inviertaencolombia. com.co/CAP1-Proteccion_a_la_Inversion_Extranjera.pdf

Procolombia (2017b). Reporte trimestral de inversión extranjera directa en Colombia. s/l: Procolombia. Recuperado el 21 de noviembre de 2017 de http://www. inviertaencolombia.com.co/publicaciones/estadisticas-ied-en-colombia.html 
Procolombia (2017c). Sectores para invertir. Portal oficial de Inversión de Colombia. Recuperado el 21 de noviembre 2017 de http://www.procolombia.co/inversionista/ sectores-para-invertir-en-colombia

Rosas Chimal, Mario Alberto, Miguel Flores Ortega y Alejandro Díaz-Bautista (2015). Flujos de capital y la calificación de riesgo país para México: 1998-2012. Análisis Económico, 30(74), 75-96.

Rothbard, Murray Newton (2012). Competition and the economists. Quarterly Journal of Austrian Economics, 15(4), 396-409.

Serrano Moya, Edgard D. (2012). Una mirada a los procesos de innovacion y desarrollo regional en algunos países de América Latina. Antropología y Sociología, 14(1), 171-207.

Sistema Interconectado Nacional (2013). Sector Energía Eléctrica. Recuperado el 3 de diciembre de 2017 de https://www.minminas.gov.co/documents/10180/ 23400/05-ENERGIA2010-2011.pdf/770a198dd4ee-4687-b74c-74592b403ae6

Stumpo, Giovanni (1999). Empresas transnacionales, procesos de reestructuración industrial y políticas económicas en América Latina. Biblioteca CEPAL. Recuperado el 21 de noviembre de 2017 de http:// repositorio.cepal.org/bitstream/handle/11362/2069/ S338098S934_es.pdf;jsessionid=F1717645757E47A E019928E9699E592B? sequence $=1$

Tirado, Ricardo (2015). Enfoques teóricos y conceptos sobre el poder político empresarial. Revista Mexicana de Ciencias Politicas y Sociales, 60(225), 311-339. https://doi.org/10.1016/s0185-1918(15)30028-3
Torres, Jaime (2013). Colombia: Inserción y desequilibrios comerciales en la Cuenca del Pacífico. Problemas del Desarrollo, 44(174), 139-165. https:// doi.org/10.1016/s0301-7036(13)71891-1

Unidad de Planeación Minero Energética (UPME) (2016). Proyección de la demanda de energía eléctrica y potencia máxima en Colombia 2016-2018. Bogotá: UPME. Recuperado el 21 de noviembre de 2017 de http:// www.siel.gov.co/siel/documentos/documentacion/ Demanda/UPME_Proyeccion_Demanda_Energia_ Electrica_Junio_2016.pdf

Vanegas López, Juan, Jorge A. Restrepo Morales y Guberney Muneton Santa (2012). Geografía económica y flujos de inversión extranjera en América Latina. Cuadernos de Administración, 28, 37-52.

Wills-Valderrama, Santiago (2011). Protección a la inversión extranjera en infraestructura por medio de acuerdos internacionales de inversión: Un nuevo reto para Colombia. International Law, 19, 17-38.

Yepes, Cristian A. (2014). El tratado de libre comercio Colombia-Estados Unidos: Análisis crítico del discurso (ACD). Suma de Negocios, 5(10), 12-21.

Recibido: 30/04/2017

Aceptado: 26/10/2017 saul.fernandez00@usc.edu.co saulrick@163.com karen8a149@yahoo.com luz_angela.martinez@uao.edu.co 